CrossMark $<$ click for updates

Cite this: Dalton Trans., 2014, 43, 17029

Received 2nd September 2014, Accepted 16th September 2014

DOI: $10.1039 / c 4 d t 02682 a$

www.rsc.org/dalton

\title{
Photocatalytic reactivity tuning by heterometal and addenda metal variation in Lindqvist polyoxometalates $\uparrow$
}

\author{
Johannes Tucher, ${ }^{a}$ Stefanie Schlicht, ${ }^{\mathrm{b}}$ Fabian Kollhoff ${ }^{\mathrm{b}}$ and Carsten Streb*a,b
}

\begin{abstract}
A systematic study into the effects of metal substitution on the visible-light photocatalytic activity of prototype metal oxide cluster anions is presented. Four isostructural Lindqvist clusters $\left[\mathrm{V}_{x} \mathrm{M}_{6-x} \mathrm{O}_{19}\right]^{(2+x)-}$ $(M=W, M o, x=1,2)$ with photooxidative activity in the visible range are reported. It is shown that the photooxidative performance correlates with the number of vanadium atoms in the cluster. Further, two divergent reaction mechanisms are observed depending on the type of addenda metal (i.e. Mo or W) used. When comparing the reactivity under aerated vs. de-aerated conditions, it was found that molybdate-based clusters show significantly increased reaction rates in the absence of oxygen; in contrast, marginally reduced reaction rates were observed for the tungstate-based species under de-aerated conditions. Wavelength-dependent quantum efficiency studies provide insight into the visible-light reactivity of all four species. Radical scavenging experiments suggest that the photocatalysis proceeds via formation of hydroxyl radicals. Cluster recycling studies demonstrate the robust nature of the homogeneous photocatalysts.
\end{abstract}

\section{Introduction}

The design of photoactive metal oxides is often limited to materials where light absorption is mainly based in the UVregion. ${ }^{1}$ This is due to a large HOMO-LUMO gap of the $\mathrm{O} \rightarrow \mathrm{M}$ ligand-to-metal charge-transfer (LMCT) transitions which form the basis of metal oxide photochemistry. ${ }^{2}$ Thus, sunlight driven photocatalyst development based on metal oxides is still a major challenge. ${ }^{3-5}$ However, one possible route is the development of molecular metal oxides, so-called polyoxometalates (POMs). POMs are high-valent metal oxide clusters formed by self-assembly of small oxometalate precursors such as $\mathrm{VO}_{4}{ }^{3-}, \mathrm{MoO}_{4}{ }^{2-}$ and $\mathrm{WO}_{4}{ }^{2-} \cdot{ }^{6-10}$ POMs combine key features of solid-state metal oxides with the structural and chemical tunability intrinsic to molecular materials. ${ }^{11}$ For this reason, POMs have been extensively used as functional molecular materials in catalysis, ${ }^{12,13}$ photocatalysis, ${ }^{14,15}$ redox-active functional materials, ${ }^{16}$ and energy conversion and storage. ${ }^{17-20}$ The chemical and structural modifications of POMs can be achieved by tuning the secondary reaction parameters (e.g. solution $\mathrm{pH}$, reaction temperature, etc.) during cluster selfassembly. ${ }^{6,7}$ This approach can also be extended to the

\footnotetext{
${ }^{a}$ Ulm University, Institute of Inorganic Chemistry I, Albert-Einstein-Allee 11, 89081 Ulm, Germany.E-mail: carsten.streb@uni-ulm.de

${ }^{b}$ Department of Chemistry and Pharmacy, Friedrich-Alexander-University ErlangenNuremberg, Egerlandstr. 1, 91058 Erlangen, Germany

$\dagger$ Electronic supplementary information (ESI) available: Experimental, analytical and catalytic details. See DOI: 10.1039/c4dt02682a
}

development of POM photocatalysts, ${ }^{14,15}$ as the electronic properties of the clusters (and therefore their visible-light photoactivity) are controlled by the underlying cluster structure. ${ }^{21-26}$ Based on this concept, functionalization routes were developed where selective metal substitution is used to photosensitize clusters in the visible region. ${ }^{23,24,26,27}$ Thus far, the concept of metal-substituted POM photocatalysts has mainly been focused on Keggin derivatives $\left[\mathrm{XM}_{12} \mathrm{O}_{40}\right]^{n-}(\mathrm{M}=\mathrm{V}, \mathrm{Mo}, \mathrm{W})^{28,29}$ whereas the development of other heterometallic, photoactive POM clusters is still in its infancy. ${ }^{30,31}$

Based on this background, we started to investigate small prototype clusters ${ }^{24}$ where selective metal exchange can be used to tune the electronic cluster properties whilst retaining the physical cluster architecture. We identified Lindqvist clusters $^{10}\left[\mathrm{M}_{6} \mathrm{O}_{19}\right]^{n-}(\mathrm{M}=\mathrm{Mo}, \mathrm{W}(n=2) \text {; Ta, Nb }(n=8))^{32,33}$ as prime model systems, since their chemical modification by metal substitution is well established. Consequently, a family of heterometallic Lindqvist clusters $\left[\mathrm{M}^{\prime}(\mathrm{L}) \mathrm{M}_{5} \mathrm{O}_{18}\right]^{n-}(\mathrm{M}=\mathrm{Mo}$, $\mathrm{W} ; \mathrm{M}^{\prime}=$ transition metal, e.g. Co, $\mathrm{V}, \mathrm{Zr}, \mathrm{Hf}, \mathrm{L}=$ ligand, e.g. $\mathrm{RO}^{-}$, $\mathrm{O}^{2-}$, etc.) is known to date. ${ }^{34-38}$

Recently, we used this synthetic concept to compare the photocatalytic performance of the non-functionalized molybdate Lindqvist $\left[\mathrm{Mo}_{6} \mathrm{O}_{19}\right]^{2-}\left(\left\{\mathbf{M o}_{6}\right\}\right)$ with the mono-vanadiumsubstituted cluster $\left[\mathrm{VMo}_{5} \mathrm{O}_{19}\right]^{3-}\left(=\left\{\mathbf{V M o}_{5}\right\}\right)$, see Fig. $1 .^{24}$ Photocatalytic tests showed that under UV and visible light irradiation, higher photoactivity was found for $\left\{\mathbf{V M o}_{5}\right\}$ than for $\left\{\mathbf{M o}_{6}\right\}$. At high wavelengths $(\lambda>450 \mathrm{~nm}),\left\{\mathbf{M o}_{6}\right\}$ was photochemically inactive whereas $\left\{\mathbf{V M o}_{5}\right\}$ still showed photooxidative activity, confirming that metal substitution is a powerful 


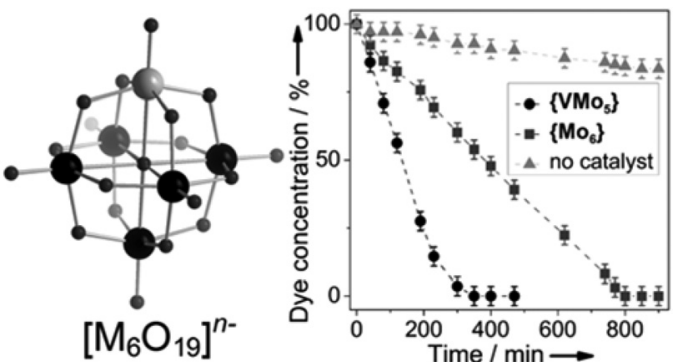

Fig. 1 Left: Illustration of the Lindqvist architecture $\left[\mathrm{M}_{6} \mathrm{O}_{19}\right]^{n-} .{ }^{24}$ Right: photooxidative performance of $\left\{\mathrm{Mo}_{6}\right\}$ and $\left\{\mathrm{VMo}_{5}\right\}$ in the photooxidation of the model pollutant dye patent blue $\mathrm{V}$ under broadband UV irradiation.

Table 1 Summary of the photocatalysts used

\begin{tabular}{lll}
\hline No. & Formula & Abbreviation \\
\hline $\mathbf{1}$ & $\left(n \mathrm{Bu}_{4} \mathrm{~N}\right)_{3}\left[\mathrm{VMo}_{5} \mathrm{O}_{19}\right]$ & $\left\{\mathbf{V M o}_{5}\right\}$ \\
$\mathbf{2}$ & $\left(n \mathrm{Bu}_{4} \mathrm{~N}\right)_{3}\left[\mathrm{VW}_{5} \mathrm{O}_{19}\right]$ & $\left\{\mathbf{V W}_{5}\right\}$ \\
$\mathbf{3}$ & $\left(n \mathrm{Bu}_{4} \mathrm{~N}\right)_{3} \mathrm{Na}\left[\mathrm{V}_{2} \mathbf{M O}_{4} \mathrm{O}_{19}\right]$ & $\left\{\mathbf{V}_{2} \mathbf{M o}_{4}\right\}$ \\
$\mathbf{4}$ & $\left(n \mathrm{Bu}_{4} \mathrm{~N}\right)_{3} \mathrm{Na}\left[\mathrm{V}_{2} \mathbf{W}_{4} \mathrm{O}_{19}\right]$ & $\left\{\mathbf{V}_{2} \mathbf{W}_{4}\right\}$
\end{tabular}

tool for tuning the visible light photoactivity of small POM clusters.

In the current report, this strategy was significantly broadened by expanding the cluster family to vanadium-functionalized molybdate and tungstate clusters and introducing monoand di-vanadium functionalized clusters. ${ }^{38}$ A summary of the photocatalysts under investigation is given in Table 1.

Here, the performance of $\mathbf{1 - 4}$ was investigated using the photooxidation of indigo (Ind) as the benchmark reaction. Several aspects of the photooxidation mechanism such as the presence of oxygen, presence of hydroxyl radical scavengers, wavelength-dependent quantum efficiencies and cluster recycling were studied to identify the most promising reaction systems.

\section{Results and discussion}

\section{Synthesis and characterization}

Compounds 1-4 were obtained by modified literature syntheses (see ESI $\dagger$ for details). ${ }^{38}$ The compounds were isolated as organo-soluble salts using tetra- $n$-butylammonium counter ions. The compounds were characterized using high-resolution electrospray ionization mass spectrometry, elemental analysis and flame atomic absorption spectroscopy; for details see ESI. $\dagger$

\section{UV-Vis spectroscopy}

UV-Vis spectroscopy of 1-4 showed that all clusters feature O-M LMCT transitions in the UV range which extend into the visible region. Notably, vanadium incorporation results in increased visible light absorption and tailing of the near UV/ Vis transitions up to $\lambda c a$. $520 \mathrm{~nm}$ was observed. In a previous

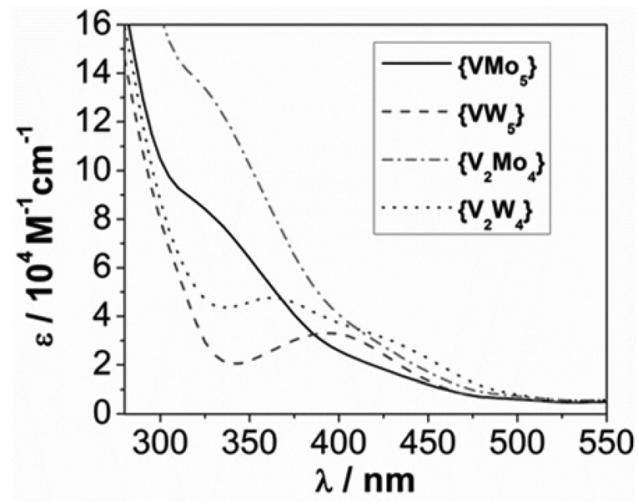

Fig. 2 UV-Vis spectra of compounds 1-4 in DMF, showing the effect of vanadium substitution on the visible light absorption.

report we showed that the visible light absorption is mainly arising from O-V LMCT transitions. ${ }^{24}$ Notably, $\left\{\mathbf{V M o}_{5}\right\}$ shows the lowest light absorption in the visible range between $\lambda=$ 400-500 nm amongst the compounds investigated, see Fig. 2. The clusters also show distinct band features in the UV range between $300-400 \mathrm{~nm}$, suggesting that the electronic cluster structure is significantly altered by vanadium incorporation.

\section{Photocatalytic studies}

Comparative photooxidation studies were performed to evaluate the photooxidative activity of $\mathbf{1 - 4}$. To this end, 1-4 were dissolved in $N, N$-dimethyl formamide (DMF) and aliquots of the model substrate indigo (Ind) were added at molar ratios [Ind] : [cluster] $=5: 1$. The homogeneous solutions were irradiated using a LED light source $(\lambda=430 \mathrm{~nm})$ in custom-built irradiation setups. Photooxidation kinetics were followed spectrometrically, see Fig. 3.

\section{Aerated conditions}

Initial experiments were focused on the performance of 1-4 under aerated conditions and obvious differences in the photooxidation kinetics were observed depending on the cluster employed. From Fig. 3, two distinct trends are obvious: (1) significantly faster reaction kinetics are observed for the tungstate species $\left\{\mathbf{V W}_{5}\right\}$ and $\left\{\mathbf{V}_{\mathbf{2}} \mathbf{W}_{\mathbf{4}}\right\}$ compared with the molybdates $\left\{\mathbf{V M o}_{5}\right\}$ and $\left\{\mathbf{V}_{2} \mathbf{M} \mathbf{o}_{4}\right\}$, see Table 2. In addition, the tungstate-based species show pseudo-first order kinetics, whereas the molybdate species feature pseudo-zeroth order kinetics. (2) Slightly faster reaction kinetics are observed for the divanadium functionalized clusters $\left\{\mathbf{V}_{2} \mathbf{M o}_{4}\right\}$ and $\left\{\mathbf{V}_{2} \mathbf{W}_{4}\right\}$ compared to the mono-vanadium species $\left\{\mathbf{V M o}_{5}\right\}$ and $\left\{\mathbf{V W}_{5}\right\}$. Quantitative insight was obtained by determining the initial observed rate constants $k_{\text {obs }}$ using a zeroth-order model; these data are summarized in Table 2.

\section{De-aerated conditions}

Next, the indigo photooxidation was investigated under deaerated conditions; this was based on previous findings where significant oxygen-related effects on the photoreactivity of 


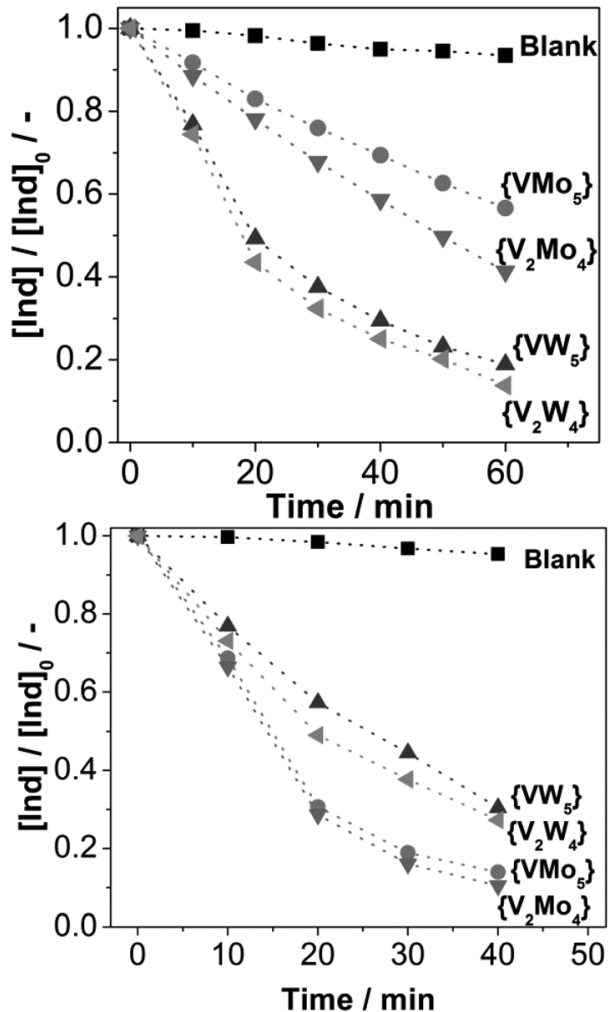

Fig. 3 Top: Photooxidation of indigo (Ind) by 1-4 under aerated conditions. Significantly faster kinetics are observed for $\left\{\mathrm{VW}_{5}\right\}$ and $\left\{\mathrm{V}_{2} \mathrm{~W}_{4}\right\}$ compared with $\left\{\mathrm{VMo}_{5}\right\}$ and $\left\{\mathrm{V}_{2} \mathrm{Mo}_{4}\right\}$. Bottom: Ind photooxidation by 1-4 under de-aerated conditions. Significantly increased reaction rates are observed for $\left\{\mathrm{VMo}_{5}\right\}$ and $\left\{\mathrm{V}_{2} \mathrm{Mo}_{4}\right\}$. For $\left\{\mathrm{VW}_{5}\right\}$ and $\left\{\mathrm{V}_{2} \mathrm{~W}_{4}\right\}$, a minor decrease in the reaction rate is observed. Conditions: solvent: DMF, [Ind] : [cluster] $=5: 1$, LED light source, $\lambda=430 \mathrm{~nm}$. De-aerated samples were flushed with $\mathrm{Ar}$ for $10 \mathrm{~min}$ prior to the experiment.

POMs were reported. ${ }^{24}$ To this end, the standard photooxidation conditions (see above) were used, but the samples were de-aerated by flushing with argon for 10 min prior to the experiment. During the photooxidation, the samples were kept under argon. Data analysis shows that a significant increase in reaction rate is observed for the molybdate-based clusters $\left\{\mathbf{V M o}_{5}\right\}(+406 \%)$ and $\left\{\mathbf{V}_{2} \mathbf{M o}_{4}\right\}(+326 \%)$; see Table 2. In contrast, for the tungstate-based clusters, the observed reaction rate is only marginally affected and a minor decrease is found: $\left\{\mathbf{V W}_{5}\right\}$
$(-16 \%)$ and $\left\{\mathbf{V}_{\mathbf{2}} \mathbf{W}_{4}\right\}(-10 \%)$. In consequence, under de-aerated conditions, the molybdate-based species are the more active photocatalysts. Notably, this observation suggests that different photooxidation mechanisms are present for the molybdate- and tungstate-based species, respectively. The photoactivity of the molybdate species is significantly reduced in the presence of oxygen, suggesting an oxygen-dependent quenching mechanism (possibly proceeding via ${ }^{3} \mathrm{O}_{2}$ triplet quenching $^{39}$ ) which limits their activity under aerated conditions. In contrast, the tungstate-based species are only marginally affected by the presence of oxygen, resulting in their superior performance under aerated conditions. ${ }^{24}$

\section{Effect of hydroxyl radical scavengers}

The effects of hydroxyl radical scavengers on the photooxidation by 1-4 were investigated to establish whether hydroxyl radicals are involved in the photooxidation mechanism. This is based on previous work which showed that POM photooxidation typically proceeds via the intermediate formation of hydroxyl radicals by reaction of cluster-bound water molecules with the photoexcited cluster. ${ }^{27}$

To this end, the standard photooxidation reaction (see above) was performed in the presence of ethanol as a standard hydroxyl radical scavenger ([EtOH] : [Ind] : [cluster] $=50: 5: 1$ ). The experiments were performed under aerated and de-aerated conditions and show almost identical behaviour: for all compounds, a significant decrease in photooxidative activity is observed (Table 2), suggesting that hydroxyl radical formation is indeed the basis of the photooxidation mechanism for all compounds under investigation.

\section{Quantum efficiency}

The wavelength-dependent quantum efficiencies of 1-4 for the aerated photooxidation of indigo were determined under monochromatic light irradiation to assess the cluster performance. ${ }^{40}$ Measurements were performed using a custom-built system in the range of $\lambda=395-505 \mathrm{~nm}$. Quantum efficiencies were found to be below $1 \%$, highlighting that the photochemically most active bands of the clusters are still in the UV region, see Table 3. The data show that higher quantum efficiencies are found for the di-vanadium substituted units

Table 2 Summary of the photooxidation parameters observed for the indigo photooxidation by $1-4^{a}$

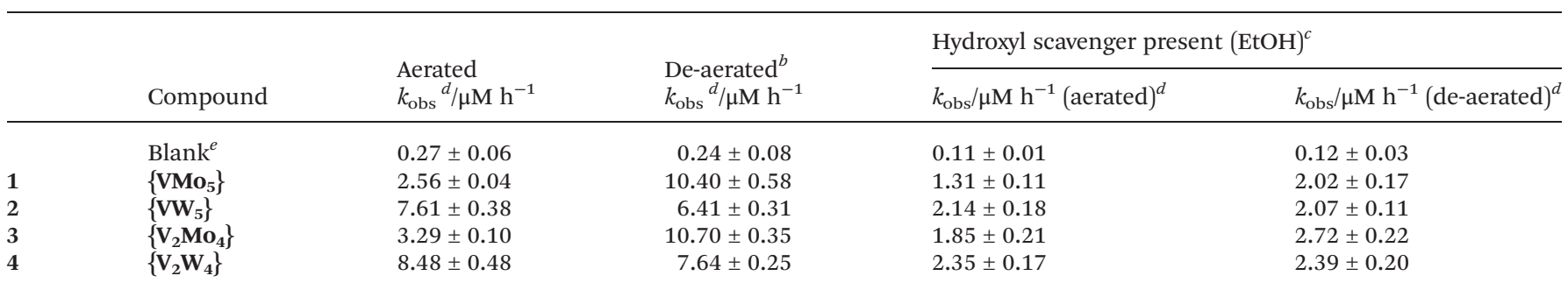

${ }^{a}$ Conditions: solvent: DMF, [Ind]: [cluster] $=5: 1$, LED light source, $\lambda=430 \mathrm{~nm} .{ }^{b}$ Samples were de-aerated by flushing with argon for $10 \mathrm{~min}$ prior to the experiment. ${ }^{c}$ [EtOH] :[Ind] : [cluster] $=50: 5: 1 .^{d} k_{\mathrm{obs}}=$ initial observed rate constant (zeroth order model). ${ }^{e}$ Blank $=$ identical reaction conditions, no photocatalyst present. 
Table 3 Quantum efficiencies $\phi$ for 1-4 observed in the photooxidation of indigo ${ }^{a}$

\begin{tabular}{lllll}
\hline$\lambda / \mathrm{nm}$ & $\phi\left(\left\{\mathrm{VMo}_{5}\right\}\right) / \%$ & $\phi\left(\left\{\mathrm{VW}_{5}\right\}\right) / \%$ & $\phi\left(\left\{\mathrm{V}_{2} \mathrm{Mo}_{4}\right\}\right) / \%$ & $\phi\left(\left\{\mathrm{V}_{2} \mathrm{~W}_{4}\right\}\right) / \%$ \\
\hline 395 & 0.2 & 0.5 & 0.73 & 0.68 \\
400 & 0.19 & 0.35 & 0.45 & 0.4 \\
410 & 0.15 & 0.2 & 0.3 & 0.28 \\
430 & 0.13 & 0.11 & 0.17 & 0.14 \\
450 & 0.11 & 0.05 & 0.09 & 0.09 \\
465 & 0.1 & 0.04 & 0.08 & 0.08 \\
505 & 0 & 0 & 0 & 0
\end{tabular}

${ }^{a}$ Conditions: solvent: DMF, [Ind $]:[$ cluster $]=1: 1 ;[$ Ind $]=[$ cluster $]=$ $1.0 \mu \mathrm{M}$.

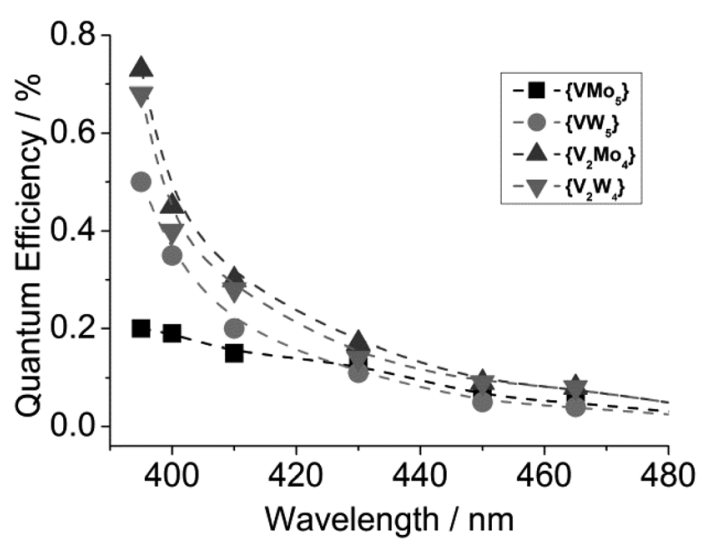

Fig. 4 Quantum efficiencies in the visible range for the indigo photooxidation by 1-4. At the UV-Vis border, higher quantum efficiencies for the di-vanadium-substituted species are observed. The tailing of the quantum efficiencies at higher wavelengths correlates with the decreasing cluster absorptivity. Conditions: solvent: DMF, [Ind] : [cluster] $=1: 1$; [Ind $]=[$ cluster $]=1.0 \mu \mathrm{M}$.

$\left\{\mathbf{V}_{2} \mathbf{M o}_{4}\right\}$ and $\left\{\mathbf{V}_{\mathbf{2}} \mathbf{W}_{4}\right\}$ and the quantum efficiency decreases with increasing wavelength (Fig. 4).

\section{Cluster recycling}

Recycling experiments were performed by conducting the standard Ind photooxidation (see above). After dye photooxidation was complete, a second aliquot of indigo was added and the photooxidation was repeated. Overall, three runs were performed under identical conditions and only a marginal decrease in dye photooxidation kinetics was observed (see ESI $\dagger$ ), suggesting that the clusters can be employed as photooxidation catalysts multiple times. Changes in the relative cluster performance over several runs are observed (e.g. decreasing rate constant for $\left\{\mathbf{V W}_{5}\right\}$ under aerated conditions) which are currently under investigation.

\section{Conclusions}

In summary, we illuminate the effects of addenda metal and heterometal on the photocatalytic performance of mixed-metal polyoxometalates: using four isostructural Lindqvist clusters
$\left[\mathrm{V}_{x} \mathrm{M}_{6-x} \mathrm{O}_{19}\right]^{(2+x)-}(\mathrm{M}=\mathrm{W}, \mathrm{Mo}, x=1,2)$ as prototypes, we report that all compounds show photoactivity up to $c a .450 \mathrm{~nm}$ and are active photooxidation catalysts. A striking difference in photoreactivity is observed when comparing tungstate- and molybdate-based clusters: under de-aerated conditions, a significant increase in photoreactivity (up to $c a .400 \%$ ) is observed for the molybdate-based species. In contrast, deaerated conditions result in a minor decrease in photoreactivity $(<c a .20 \%)$ for the tungstate clusters. Under aerated conditions, the tungstate-based systems feature higher reactivity than the molybdate systems. The findings suggest that oxygen quenches photoreactivity for the molybdates but not for the tungstates and two different reaction mechanisms must therefore be present. Further, mechanistic studies show that all four compounds feature drastically reduced reactivity in the presence of hydroxyl radical scavengers, providing evidence that $\mathrm{OH}$ radicals are formed as reactive intermediates during irradiation.

Future work will use photophysical and computational analyses so as to determine the underlying mechanism of the divergent reactivity of molybdate and tungstate Lindqvists. The clusters will be screened for use in technologically relevant photooxidation reactions such as alcohol and olefin oxidations.

\section{Experimental section}

For synthetic details of compounds 1-4, see ESI. $\dagger$

Elemental analysis for 1: $\mathrm{C}_{48} \mathrm{H}_{108} \mathrm{~N}_{3} \mathrm{VMo}_{5} \mathrm{O}_{19}\left(M_{\mathrm{w}}: 1562.02 \mathrm{~g}\right.$ $\mathrm{mol}^{-1}$ ) in wt\% (calcd): C 37.09 (36.91), H 7.15 (6.97), N 2.84 (2.69), V 2.62 (3.24), Mo 31.91 (31.16). The cluster anion observed in ESI-MS: 1077.66 (calcd: 1077.68), assigned as $\left\{\left(n \mathrm{Bu}_{4} \mathrm{~N}\right) \mathrm{H}\left[\mathrm{VMo}_{5} \mathrm{O}_{19}\right]\right\}^{-}$.

Elemental analysis for 2: $\mathrm{C}_{48} \mathrm{H}_{108} \mathrm{~N}_{3} \mathrm{VW}_{5} \mathrm{O}_{19}\left(M_{\mathrm{w}}\right.$ : $2001.52 \mathrm{~g}$ $\mathrm{mol}^{-1}$ ) in wt\% (calcd): C 29.07 (28.80), H 5.52 (5.44), N 2.12 (2.10), V 2.04 (2.55), W 45.31 (45.93). The cluster anion observed in ESI-MS: 1759.15 (calcd: 1759.16), assigned as $\left\{\left(n \mathrm{Bu}_{4} \mathrm{~N}\right)_{2} \mathrm{VW}_{5} \mathrm{O}_{19}\right\}^{-}$.

Elemental analysis for $3: \mathrm{C}_{48} \mathrm{H}_{108} \mathrm{~N}_{3} \mathrm{NaV}_{2} \mathrm{Mo}_{4} \mathrm{O}_{19} \quad\left(M_{\mathrm{w}}\right.$ : $1540.01 \mathrm{~g} \mathrm{~mol}^{-1}$ ) in wt\% (calcd): C 37.04 (37.44), H 7.03 (7.07), N 2.70 (2.73), Na 1.38 (1.49), V 6.12 (6.62), Mo 24.79 (24.92). The cluster anion observed in ESI-MS: 1319.91 (calcd: 1319.89), assigned as $\left\{\left(n \mathrm{Bu}_{4} \mathrm{~N}\right)_{2}(\mathrm{MeCN})_{5} \mathrm{Na}\left(\mathrm{H}_{2} \mathrm{O}\right)_{6}\left[\mathrm{~V}_{2} \mathrm{Mo}_{4} \mathrm{O}_{19}\right]\right\}^{-}$.

Elemental analysis for 4: $\mathrm{C}_{48} \mathrm{H}_{108} \mathrm{~N}_{3} \mathrm{NaV}_{2} \mathrm{~W}_{4} \mathrm{O}_{19} \quad\left(M_{\mathrm{w}}\right.$ : $1891.61 \mathrm{~g} \mathrm{~mol}^{-1}$ ) in wt\% (calcd): C 30.04 (30.48), H 5.73 (5.75), N 2.18 (2.22), Na 1.12 (1.22), V 7.08 (7.09), W 50.79 (51.14). The cluster anion observed in ESI-MS: 606.84 (calcd: 606.84), assigned as $\left\{\left(\mathrm{NH}_{4}\right)_{2}\left(\mathrm{H}_{2} \mathrm{O}\right)_{2} \mathrm{~V}_{2} \mathrm{~W}_{4} \mathrm{O}_{19}\right\}^{2-}$.

Photocatalytic measurements: the standard indigo photooxidation was carried out as follows: an $N, N$-dimethyl formamide (DMF) solution of the respective cluster $(1.0 \mu \mathrm{M})$ and indigo $(5.0 \mu \mathrm{M})$ was prepared. The homogeneous solution was irradiated with a custom-built LED irradiation setup (standard light source: $\lambda=430 \mathrm{~nm}, P_{\text {nominal }}=3 \mathrm{~W}$, other wavelengths are stated in the text). Indigo photooxidation was detected spectro- 
metrically by following the decrease of the characteristic absorption signal at $\lambda_{\max }=609 \mathrm{~nm}$. De-aerated experiments were performed by flushing the sample with Ar for $10 \mathrm{~min}$ prior to the experiment. Hydroxyl radical scavenging experiments were performed by adding ethanol $(50 \mu \mathrm{M})$ to the solution.

\section{Acknowledgements}

Funding by the Deutsche Forschungsgemeinschaft (contract no. STR1164/4-1), Ulm University and GRK1626 is gratefully acknowledged. C.S. acknowledges the Fonds der chemischen Industrie for a Liebig-Fellowship. Prof. Dr I. Ivanovic-Burmazovic and O. Troeppner are acknowledged for ESI-MS measurements.

\section{Notes and references}

1 R. van de Krol, Y. Liang and J. Schoonman, J. Mater. Chem., 2008, 18, 2311-2320.

2 H.-J. Zhai, J. Döbler, J. Sauer and L.-S. Wang, J. Am. Chem. Soc., 2007, 129, 13270-13276.

3 K. Hashimoto, H. Irie and A. Fujishima, Jpn. J. Appl. Phys., 2005, 44, 8269.

4 D. Zhang, G. Li, H. Li and Y. Lu, Chem. - Asian J., 2013, 8, 26-40.

5 A. Kudo, Pure Appl. Chem., 2007, 79, 1917-1927.

6 D. L. Long, R. Tsunashima and L. Cronin, Angew. Chem., Int. Ed., 2010, 49, 1736-1758.

7 D. L. Long, E. Burkholder and L. Cronin, Chem. Soc. Rev., 2007, 36, 105-121.

8 Special POM issue: C. Hill (guest ed.), Chem. Rev, 1998, 98, 1.

9 M. T. Pope and A. Müller, Angew. Chem., Int. Ed. Engl., 1991, 30, 34-48.

10 M. T. Pope, Heteropoly and isopoly oxometalates, SpringerVerlag, Heidelberg, 1983.

11 Special POM issue: L. Cronin and A. Müller (guest eds.), Chem. Soc. Rev, 2012, 41, 7325-7648.

12 C. L. Hill and C. M. Prosser-Mccartha, Coord. Chem. Rev., 1995, 143, 407-455.

13 C. L. Hill, J. Mol. Catal. A: Chem., 2007, 262, 2-6.

14 C. L. Hill and C. M. Prosser-McCartha, in Photosensitization and Photocatalysis using inorganic and organometallic compounds, ed. M. Graetzel and K. Kalyanasundaram, Kluwer Academic Publishers, Dordrecht, 1993, pp. 307-326.

15 E. Papaconstantinou and A. Hiskia, in Polyoxometalate Molecular Science, ed. J. J. Borras-Almenar, E. Coronado, A. Mueller and M. T. Pope, Kluwer Academic Publishers, Dordrecht, 2003, pp. 381-416.

16 S. G. Mitchell, C. Streb, H. N. Miras, T. Boyd, D.-L. Long and L. Cronin, Nat. Chem., 2010, 2, 308-312.
17 B. Botar, Y. V. Geletii, P. Kögerler, D. A. Hillesheim, D. G. Musaev and C. L. Hill, Angew. Chem., Int. Ed., 2008, 47, 3896-3899.

18 Y. V. Geletii, Z. Q. Huang, Y. Hou, D. G. Musaev, T. Q. Lian and C. L. Hill, J. Am. Chem. Soc., 2009, 131, 7522-7524.

19 A. Sartorel, M. Carraro, G. Scorrano, R. De Zorzi, S. Geremia, N. D. McDaniel, S. Bernhard and M. Bonchio, J. Am. Chem. Soc., 2008, 130, 5006-5009.

20 Q. S. Yin, J. M. Tan, C. Besson, Y. V. Geletii, D. G. Musaev, A. E. Kuznetsov, Z. Luo, K. I. Hardcastle and C. L. Hill, Science, 2010, 328, 342-345.

21 X. Lopez, J. J. Carbo, C. Bo and J. M. Poblet, Chem. Soc. Rev., 2012, 41, 7537-7571.

22 J. Forster, B. Rösner, M. M. Khusniyarov and C. Streb, Chem. Commun., 2011, 47, 3114-3116.

23 (a) J. Tucher, L. C. Nye, I. Ivanovic-Burmazovic, A. Notarnicola and C. Streb, Chem. - Eur. J., 2012, 18, 10949-10953; (b) J. Tucher and C. Streb, Beilstein J. Nanotechnol., 2014, 5, 711-716.

24 J. Tucher, Y. L. Wu, L. C. Nye, I. Ivanovic-Burmazovic, M. M. Khusniyarov and C. Streb, Dalton Trans., 2012, 41, 9938-9943.

25 C. Streb, K. Kastner and J. Tucher, in Chemical Photocatalysis, ed. B. König, De Gruyter, Berlin, 2013, pp. 247-258.

26 A. Seliverstov and C. Streb, Chem. Commun., 2014, 50, 1827-1829.

27 C. Streb, Dalton Trans., 2012, 41, 1651-1659.

28 C. L. Hill, in Comprehensive Coordination Chemistry II, ed. J. A. McCleverty and T. J. Meyer, Elsevier, Oxford, 2004, vol. 4, pp. 679-759.

29 E. N. Glass, J. Fielden, A. L. Kaledin, D. G. Musaev, T. Lian and C. L. Hill, Chem. - Eur. J., 2014, 20, 4297-4307.

30 J. Ettedgui, Y. Diskin-Posner, L. Weiner and R. Neumann, J. Am. Chem. Soc., 2011, 133, 188-190.

31 A. M. Khenkin, I. Efremenko, L. Weiner, J. M. L. Martin and R. Neumann, Chem. - Eur. J., 2010, 16, 1356-1364.

32 M. Nyman, Dalton Trans., 2011, 40, 8049-8058.

33 T. M. Anderson, M. A. Rodriguez, F. Bonhomme, J. N. Bixler, T. M. Alama and M. Nyman, Dalton Trans., 2007, 4517-4522.

34 R. J. Errington, L. Coyle, P. S. Middleton, C. J. Murphy, W. Clegg and R. W. Harrington, J. Cluster. Sci., 2010, 21, 503-514.

35 R. J. Errington, G. Harle, W. Clegg and R. W. Harrington, Eur. J. Inorg. Chem., 2009, 5240-5246.

36 R. J. Errington, S. S. Petkar, P. S. Middleton and W. McFarlane, J. Am. Chem. Soc., 2007, 129, 12181-12196.

37 R. J. Errington, S. S. Petkar, B. R. Horrocks, A. Houlton, L. H. Lie and S. N. Patole, Angew. Chem., Int. Ed., 2005, 44, 1254-1257.

38 M. Filowitz, R. K. C. Ho, W. G. Klemperer and W. Shum, Inorg. Chem., 1979, 18, 93-103.

39 L. Patterson, G. Porter and M. Topp, Chem. Phys. Lett., 1970, 7, 612-614.

40 U. Megerle, R. Lechner, B. Konig and E. Riedle, Photochem. Photobiol. Sci., 2010, 9, 1400-1406. 